\title{
Selçuklularda Kullanılan Batılı Bir Unvan: Kondistabl
}

\author{
Mustafa DAŞ \\ Prof. Dr., Dokuz Eylül Üniversitesi, Edebiyat Fakültesi, Tarih Bölümü, İzmir, Türkiye \\ mustafa.das@deu.edu.tr (Sorumlu Yazar/Corresponding Author)
}

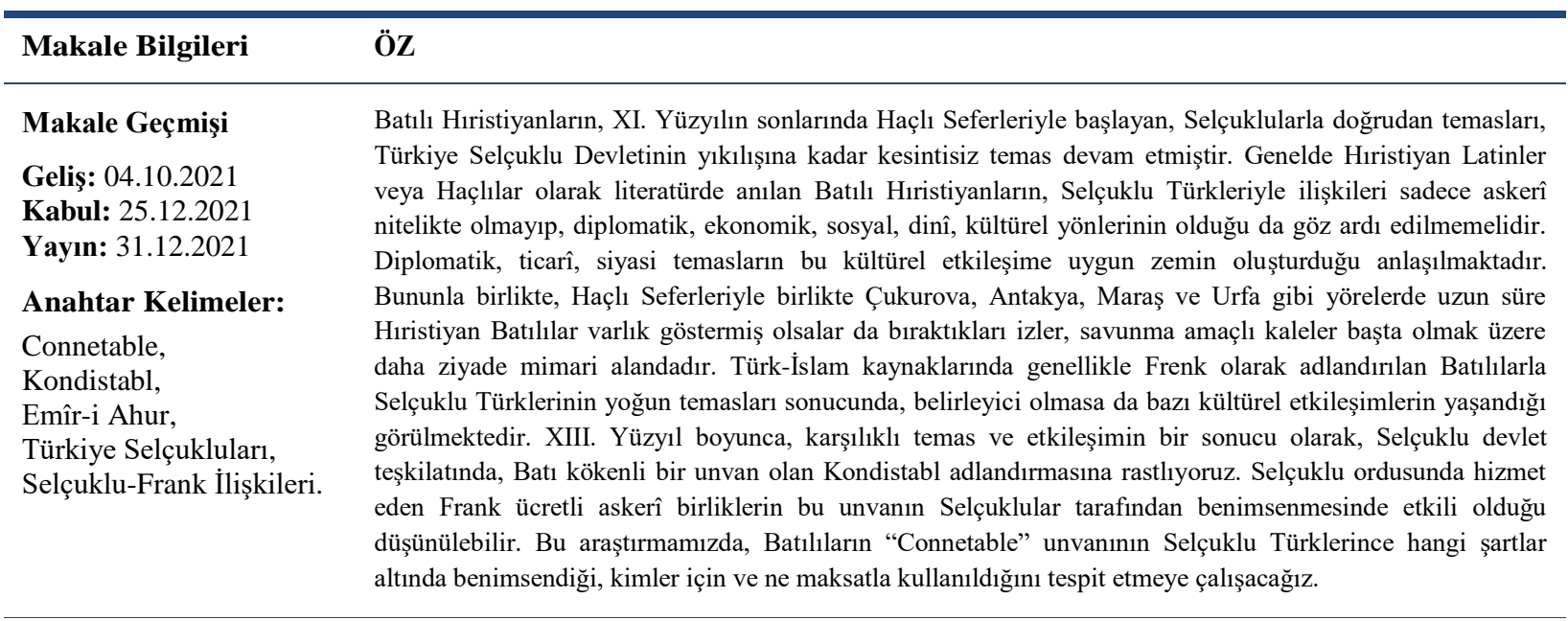

\section{A Western Title Used in the Seljuks: Kondistabl}

\begin{tabular}{ll}
\hline Article Info & ABSTRACT \\
\hline Article History & $\begin{array}{l}\text { Western Christians, the direct relations of whom with the Seljuks, started with the Crusades at the end of the XI. } \\
\text { century, continued uninterrupted until the collapse of the Turkish Seljuk State. It should not be overlooked that }\end{array}$ \\
$\begin{array}{l}\text { Received: } 04.10 .2021 \\
\text { Accepted: } 25.12 .2021\end{array}$ & $\begin{array}{l}\text { military relations with the Seljuk Turks, but also diplomatic, economic, social, religious and cultural aspects. It is } \\
\text { understood that diplomatic, commercial, political relations have laid the foundations of this cultural interaction. }\end{array}$ \\
$\begin{array}{l}\text { Published: } 31.12 .2021 \\
\text { Keywords: }\end{array}$ & $\begin{array}{l}\text { Furthermore, although the Western Crusaders have remained in the regions such as Cukurova, Antakya, Maras and } \\
\text { Urfa along with the Crusades, the traces they left, especially the defensive castles, were rather in the architectural } \\
\text { realm. As a result of these intense contacts between the Westerners, who are usually called Franks in Turkish-Islamic }\end{array}$ \\
$\begin{array}{l}\text { Connetable, } \\
\text { Kondistabl, }\end{array}$ & $\begin{array}{l}\text { sources, and the Seljuk Turks, it is seen that some cultural interactions, although not decisive, took place. Throughout } \\
\text { the XIIIth century, due to the mutual contact and interaction, we come across the name Kondistabl, a title of Western } \\
\text { Emîr-i Ahur Turkish, } \\
\text { Seljuks, }\end{array}$ \\
origin, in the Seljuk State organization. In this research, we will try to determine under what conditions the title of \\
Seljuk-Frank Relations.
\end{tabular}

Atıf/Citation: Daş, Mustafa. "Selçuklularda Kullanılan Batılı Bir Unvan: Kondistabl”. Selçuklu Medeniyeti Araştırmaları Dergisi (SEMA) 6 (Aralık 2021), 126-132. https://doi.org/10.47702/sema.2021.19

"This article is licensed under a Creative Commons Attribution-NonCommercial 4.0 International License (CC BY-NC 4.0)" 


\section{GİRIŞ}

Anadolu ve Yakındoğu coğrafyasında Türkler ve Batı Avrupalı Hıristiyanların ilk karşılaşmaları ve kesintisiz temaslarının başlaması, 25 Kasım 1095 yılında ilan edilen Haçlı Seferleri dolayısıyla meydana gelmiştir. "Kutsal Toprakları Kurtarmak" ana gerekçesiyle 1096'da Batı Hıristiyanlığı tarihinin en büyük ordularını toplayıp, 1097'de Anadolu'ya Selçuklu topraklarına saldırdılar'. Türkiye Selçuklularının başkenti İznik'i kuşatan Haçlılar, şehrin Bizans'a teslim olmasından sonra Dorylaion'da Selçuklu kuvvetlerini mağlup ettiler. Anadolu'yu yağma, katliam, kan ve ateşe boğarak geçen Haçlılar, Ekim 1097'de Antakya'yı kuşattılar. Bu arada ana Haçlı ordusundan ayrılan bir grup, Urfa'ya kadar ilerleyip, burada hâkimiyet kurdu². Uzun süren kuşatma ve Emir Kürboğa idaresindeki İslam ordusunun başarısızlı̆̆ı sonrasında, Antakya'yı zapt eden Haçlılar, yürüyüşlerine devam ederek, en nihayetinde 15 Temmuz 1099'da Kudüs'ü zapt ettiler ve hedeflerine ulaştılar. Başta Kudüs olmak üzere Urfa, Antakya ve Trablusşam'da devletler kuran ve farklı yerlerde senyörlükler oluşturan Batı Avrupalı Hıristiyanlar, iki asırdan fazla bir süre için artık Türkler ve diğer Müslüman toplumlarla komşu olarak yan yana hatta iç içe yaşayacaklardır. Başlangıcı ve doğası gereği Batılı Hıristiyanlarla, Müslümanların münasebetleri, tarihi kaynaklarda askerî yönüyle her zaman ön plana çıkmıştır. Oysaki sürüp giden Hilal-Haç savaşına paralel olarak Batı Avrupa kökenli Hıristiyanlarla, Anadolu ve Yakındoğu'daki Müslümanlar, yaşadıkları ortak topraklar üzerinde bir modus vivendi (asgari müşterekleri kabul ederek bir arada yaşama) geliştirmişlerdir. Her iki tarafta zamanla bir birlerinin dillerini, kültürlerini, yaşam tarzlarını tanımışlar ve bu bağlamda sosyal, ekonomik-ticari, diplomatik ve kültürel ilişkiler kurmuşlardır³ ${ }^{3}$.

Müslüman tarihi kaynakları (Arapça, Farsça, Türkçe) Batılı Hıristiyanları genelde ortak bir adla, Frenk (Afranj, İfrenj) olarak isimlendirirler ${ }^{4}$. Frenk aynı zamanda, duruma göre "Fransızları" veya "Frankları" da ifade etmektedir. İlk Haçlı Seferi ve 1101 Haçlı Savaşlarının yıkıcı etkileri durulduktan sonra hem Müslüman iktidar sahipleri hem de Hıristiyan Frenkler, bir birlerinin varlıklarını kabullenmişler ve hatta aralarında iki komşu arasında rastlanılması "normal" kabul edilen temaslar geliştirilmişlerdir. Bu minvalde Müslüman bir Emir ile bir Frenk Lordun çıkarları gereğince, askerî ittifak yaptıkları dahi görülmüştür. Nitekim 1108'deki, Tell-Bâşir savaşında Musul Emiri Çavlı ile Urfa hâkimi Baudouin de Boulogne müttefik olarak Halep Meliki Rıdvan ile Antakya Prensi Tankred ittifakına karşı savaştılar. Y Yine aynı yılın sonlarına doğru, ticarî-ekonomik sebeplerin zorlamasıyla Emir Tuğtekin ve Baudouin, Sevâd ve Aclûn bölgelerinin, yani Mâverây-1 Ürdün bölgesinin gelirlerini aralarında paylaşmak şartıyla on yıllık bir anlaşma yaptılar ${ }^{6}$.

Türkiye Selçukluları sahasında yani Anadolu'da, XII. Yüzyılda, Urfa'nın geri alınması (1144), II. Haçlı Seferi (1147-1149) ve Friedrich Barbarossa'nın Haçlı Seferi (1189-1190) gibi sarsıcı, büyük gelişme ve çatışmalar sonrasında, Selçuklu Türkleriyle Frenkler arasında, artık karşılıklı ilişkilerin komşuluğa dayalı "barışçı" yönleri de ön plana çıkmaya başlamıştır. Diğer taraftan Türkiye Selçuklu Devleti kuruluşundan itibaren Anadolu'da, Hıristiyan halka yönelik geliştirdiği hoşgörü (istimalet) politikasını son derece başarıyla uygulayarak, devlet ile Müslim ve Gayr-i Müslim unsurlardan oluşan tebaasını bütünleştirmişti. Hukuken zımmî statüdeki Selçuklunun Hıristiyan halkı, güvence altındaki

\footnotetext{
${ }^{1}$ Haçlı Seferleri için, I. Demirkent, Haçlı Seferleri (İstanbul: Dünya Yayıncılık, 2004); S. Runciman, Haçlı Seferleri Tarihi, çev. F. Işıltan, 3. Cilt (Ankara: TTK, 1986); H. Lamb, Haçlı Seferleri, çev. F. Dikmen (Ankara, Tutku Yayınevi, 2012).

2 I. Demirkent, Urfa Haçlı Kontluğu (1098-1118), I. Cilt (Ankara: TTK, 1990).

${ }^{3} \mathrm{Bu}$ konuda akademik niteliği olmasa da Amin Maalouf, Arapların Gözüyle Haçlı Seferleri, çev. M. Ali K1lıçbay (İstanbul: Telos Yayıncılık, 1997).

${ }^{4}$ B. Lewis, "Ifranj”, Encyclopédie de l'Islam (Leiden: BRILL, 2003), 4/16, 189-204.

${ }^{5}$ Demirkent, Urfa Haçlı Kontluğu, 119-125

${ }^{6}$ Runciman, Haçlı Seferleri, II, 79.
} 
din ve inanç hürriyetinden, çağının çok ilerisinde bir şekilde, faydalanıyor ve çoğu zaman Müslüman olmaksızın devlet kademelerinde görevler dahi alabiliyorlardı ${ }^{7}$. Selçuklu Anadolu'sunda, emsaline başka coğrafyalarda az rastlanılır nitelikte, geliştirilen "birlikte yaşam kültürü” doğal olarak, toplumlar arasında her alanda karşılıklı etkileşime ve hümanist özellikte yeni anlayışlara, pragmatist nitelikte de yeni uygulamalara yol açmıştır ${ }^{8}$.

Çatışmaların yaşanmadığı dönemlerde Selçuklularla temasa geçen Batı kökenli Frenkler, Hıristiyanların büyük bir hoşgörüyle karşılandığı Anadolu'da, devlet bünyesinde ücretli askerler olarak kendilerine yer bulabilmişlerdir. Selçuklu askerî teşkilatında, çeşitli milletlerden ve dinden olan kişilerden ücretli askerler bulundurulabiliyordu. Ecrihor adıyla bilinen ücretli askerler, "herhangi bir sefer zarfında hizmet vermek üzere kiralanan ve bunun karş1lı̆̆ında belirli bir ücret" alıyorlardı" Bununla birlikte, E. Göksu'nun da işaret ettiği üzere, Türkiye Selçuklularında, ücretli askerler ordu teşkilatında belirleyici, asli unsur olmamışlardır ${ }^{10}$. XIII. Yüzyılda Selçuklular ücretli asker ihtiyacının büyük bir kısmını Hıristiyanlar arasından karşılamaktaydı. İbn Bîbî, Yassıçemen Savaşında, "Türk, Arap, Frenk, Gürci, Rumî, Rus askerlerin" bulunduğunu kaydediyor ${ }^{11}$. Ücretli Frenk askerlerinin Selçuklu ülkesindeki en büyük başarısı Babaî İsyanının bastırılması olsa gerektir. Dönemin çağdaş kaynağı Simon de Saint Quentin'e göre, isyancılar Türkiye'yi yok etmek üzereydiler. Türkler korkularından asîlerin üzerine gidemiyor, kaçıyorlardı. 300 Latin, yani Frenk, asîlerin toplandığı yere giderek, 11.000 kişiden oluşan isyancıların üzerine atıldılar. Hepsini yok ettiler. Sadece bir Latin ölmüştü ama çok yaralı vardı. Böylece Latinlerin, Baba İshak üzerinde zafer kazanmalarının ardından Sultan 300.000 soldanus (sultani, altın para) verilmesini emretti ${ }^{12}$. İbn Bibi, Kösedağ savaşında da yine ücretli Frenk askerlerin varlığına işaret ediyor: "Ayrıca Sis hükümdarının da ü̧̈ bin kişilik Ermen ve Frank süvariyle iki gün sonra bize katılacağı haberini aldık. Onların fazla kişiyle bize katılmaları bizim için büyük destek olur"; "Gürcü oğlu, Veliiyeddin pervane, Nasuheddin Farsi ve diğer asker sahipleri ve komutanlar büyük bir cesaretle canlarını hiçe sayarak üç bin Frank ve Rum süvariyle geyiklerin bile sarp iniş ve çıkışlarında yürüyüp gezinemeyeceği geçitlerden yılan gibi aktılar"13.

XIII. Yüzyılın başlarından itibaren Selçuklu sultanları, Doğu Akdeniz kıyısındaki Batılı Frenkler arasından, dikkat çekici sayıda ücretli askerler (ecrihor) getirtmişlerdir. Savaşçılıkları, Sultana itaatkârlıkları ve cesaretleriyle ünlenen Frenk askerleri, zaman zaman Sultan'ın en yakın korumalığını yapan birlikler olmuşlardır. Büyük Alaeddin Keykubad'ın başkent Konya'ya girişi ve saltanat tahtına oturuşunu anlatan İbn Bibi, Sultan'ın yakın korumasını yapan askerleri şöyle anlatmaktadır: "Her biri şeytan yüzlü, ejderha huylu, .... Ecelden daha hızlı merhametsiz, kiyamet gününden daha karanlık, semavi felaketlerden daha katı ve ani ölümlerden daha yüzsüz olan Kazvinli, Deylemli, Frenk, Rum ve Rus beş yüz çavuş demir topuz, gürz ve nacaklartyla devlet sahibinin rikabının yanında koşuyorlardı"14. Selçuklu sultanının Frenk muhafızlarına ilişkin bir başka tarihi kaynak ifadesi; Sultan İzzeddin Keykavus'un, Mengücek Beyi Behramşah'ın kızıyla evliliği

\footnotetext{
${ }^{7}$ Selçuklular birçok Hıristiyan devlet adamını çeşitli görevlere getirmişlerdir. Örneğin Sinop fethedildiğinde, Ermeni kökenli Hetum vali olarak atanmıştır. C. Cahen, Osmanlılardan Önce Anadolu, çev. E. Üyepazarcı (İstanbul: TVYY, 2000), 70.

${ }^{8}$ M. Balivet, Romanie Byzantine et Pays de Rûm Turc. Histoire d'un Espace d'Imbrication Greco-Turque, İstanbul: 1990, N. Altunsoy, Türkiye Selçukluları Döneminde Gayrimüslimler (Ankara: TTK, 2021).

${ }^{9}$ E. Göksu, Türkiye Selçuklularında Ordu (Ankara: TTK, 2010), 113-114.

${ }^{10}$ Göksu, Türkiye Selçuklularında Ordu, 114-115.

${ }^{11}$ İbn Bibi, El-Evâmirü'l-Alâ'iyye fi'l-Umûri'l-Alâ'iyye Selçukname II, çev. M. Öztürk (Ankara: TTK, 2014), 388

${ }^{12}$ Simon de Saint Quentin, Bir Keşişin Anılarında Tatarlar ve Anadolu 1245-1248, çev. E. Özbayoğlu (Antalya: DAKTAV, 2006), s. 44-45; Göksu, Türkiye Selçuklularında Ordu, 146.

${ }^{13}$ İbn Bibi, El-Evamir, 497, 499.

${ }^{14}$ İbn Bibi, El-Evâmir, 239-240.
} 
dolayısıyla, halka açık yapılan bir toplantı sırasında, "Kazvinli, Deylemli Rum ve Frenk serhengler, ellerinde bayrakları ve hançerleriyle samanyolu yıldızları gibi ayakta durdular" ". Taht kavgalarında Frenk ücretli askerlerinin desteği her zaman aranan ve tercih edilen nitelikteydi. Nitekim 1237'de, Saadettin Köpek'in entrikasıyla II. Gıyaseddin Keyhüsrev tahta çıkarken en büyük desteği, ücretli Frenk askerleri vermişti. Saadettin, bu Latin ve Frenk askerlere, "İşte efendiniz ve Sultanınız! Onu tahta çıkarınız" diye hitap etmişti ${ }^{16}$.

Selçuklu ülkesinde ücretli Frenk askerlerinin istihdam edilmeleriyle birlikte, Selçuklular arasında Batı kökenli yeni bir unvan, "Kondistabl" adlandırılmasıyla karşılaşıyoruz. Latince "comes stabuli" [Süvari, Ahır Kontu], Fransızca önceleri "comte de l'étable", daha sonralarıysa "connetable" olarak ifade edilmiştir. Hükümdarın savaş̧̧ı yoldaşı anlamındaki "comes", erken Ortaçağ' da "kont" şeklini almış ve feodal çağdaysa, hükümdarın soylu vasalı ve erk sahibi olarak geniş toprakların yöneticisini ifade etmiştir. Kont unvanındaki bu gelişmeye bağlı olsa gerek, feodal dönemde süvari birliklerinin komutanları, konttan daha farklı olarak "connetable/konetabl" adıyla anılması yaygınlık kazanmıştır ${ }^{17}$. Merovenj'ler ${ }^{18}$ döneminde süvari birliklerinin komutanlarına bu unvan verilirken, devlet ordusunun komutası hanedan prenslerine münhasır kaldı ve hiçbir connetable, "başkomutan" mevkiine getirilmedi. Capétien'ler ${ }^{19}$ dönemindeyse, "Fransa Connetable' 1 " mevkii ihdas edilerek, hanedan mensubu şövalye prenslerden birine tevdi edildi ${ }^{20}$. Feodal Çağ ve Haçlı Seferleri döneminde, savaşçılıklarıyla Batılı Hıristiyan orduların başat unsuru olan zırhlı süvariler, connetable'lar tarafından sevk ve idare edildiler. Connetable'lar devlet görevlisi sayıldığından tenure/dirlik verilmez, maaş alırlardı. Haçlı Seferleriyle Doğu Akdeniz ve Yakındoğu coğrafyasında tanınmaya başlayan connetable'llk, özellikle Hiristiyan devlet ve toplumlar (Bizans ve Ermeniler) arasında ilgiyle karşılandı. Bizans'ta süvari birlikleri komutanlığı için "Konostavlos" unvan ve görevi ihdas edildi ${ }^{21}$.

Nitekim Selçuklu kaynaklarında Kondistabl unvanı ilk defa Ermeniler arasında zikredilmektedir. Selçuklu Sultanı I. İzzeddin Keykavus, 1216'da Kilikya Ermenilerinin yaptıkları saldırganlığı cezalandırmak ve işgal edilen kaleleri geri almak için sefere çıktı ${ }^{22}$. Bu seferle ilgili gelişmeleri anlatan İbn Bibi, Ermeni Leon'un, “ordusunun güç kaynağı ve askerlerinin öncüsü olan Baron Vasil, Baron Oşin ve Kont Stabl'ıyı yanına çağırıp, onları savaş konusunda cesaretlendirdi" demek suretiyle, Ermeniler arasında Connetable / Kondistabl unvanının kullanıldığını ve bu unvanın Selçuklu çevrelerinde de artık tanındığını göstermektedir ${ }^{23}$.

Selçuklu devlet teşkilatında Kondistabl unvanı ilk defa Emir Esededdin Ayaz ${ }^{24}$ için kullanılmıştır. Alaeddin Keykubad döneminin ünlü devlet adamlarından biri olan ve Ayas-1 Mecnun adıyla da bilinen Emir Esededdin'e bu unvanın Alanya'nın fethi öncesinde verildiği anlaşılıyor. İbn

\footnotetext{
15 İbn Bibi, El-Evâmir, 201.

${ }^{16}$ O. Turan, Selçuklular Zamanında Türkiye Tarihi (İstanbul: Nakışlar Yayınevi, 1984), 405.

${ }^{17}$ G. Rodolphe, "Le Grand Connétable", Recherches sur les institutions byzantines (Berlin-Amsterdam: 1967), 469-477.

${ }^{18}$ Günümüz Fransa'sında, V.-VII. yüzyıllarda hüküm sürmüş olan Frank hanedanı ve krallığı.

${ }^{19}$ Fransa Krallığını 987'den 1792'ye kadar yönetmiş olan hanedan.

${ }^{20}$ J. Favier, "Connetable", Encylopedia Universalis. (Erişim 10 Ekim 2021).

${ }^{21}$ A. Kazhdan, "Komes tou staulo" ve "Konostaulos", The Oxford Dictionary of Byzantium, (Oxford: Oxford University Press 2007), 1140, 1147.

${ }_{22}^{2}$ M. Ersan, Selçuklular Zamanında Anadolu'da Ermeniler (Ankara: TTK, 2007), 168-170.

23 İbn Bibi, El-Evâmir, 193.

${ }^{24}$ Mehmet Ali Hacigökmen, "Türkiye Selçuklu Devlet Adamlarından Eseddedin Ayaz”, Selçuk Üniversitesi Türkiyat Araştırmaları Dergisi, 27, (2010), 471-488. Kondistabl Emir Eseddeddin Ayas, I. G1yaseddin Keyhüsre'in sürgündeyken hizmetinde bulunmuş, onunla birlikte nekbete uğramış, güçlük çekmiş, tecrübeli bir kumandan olarak tanıtılmaktadır, Mehmet Ali Köymen, Büyük Alâeddin Keykubad ve Zamanı, yay. haz. Salim Koca-Sinan Tarifci (İstanbul: Kronik, 2020), 249.
} 
Bibi'nin Farsça metninde kond-i stabl şeklinde geçen unvanı, metni Türkçeye kazandıran M. Öztürk, parantez içinde vererek Emir-i Ahur olarak kaydetmeyi uygun görmüştür ${ }^{25}$. Çemişkezek'in fethi sırasında da Selçuklu kaynağı Esededdin Ayaz'dan, sürekli olarak "Emir Kondistabl" şeklinde bahsetmektedir: "Malatya subaşısı Kondistabl Emir Esededdin, padişahın emriyle muzaffer askerlerden beş bin süvari seçip savaş ve kuşatma aletleriyle Çemişkezek kalesine yürüdü"; "Emir Kondistabl, orya varıp kaleye bir göz atınca yanındaki sipehdârlara ve serverlere ... böyle bir yer savaşla alınamaz"; "Elçi dönüp durumu anlatınca, Kondistabl, söz kapısını kapattıklarına göre bize savaş açmak düşüyor"; "O sirada Kondistabl, ordu komutanına, şan ve şeref peşinde koşan .... Savaşçı yiğitler gelsin"; "Kondistable, çaresizlikten kıvranıp dururken ... ansızın hoş simalı, güzel yüzlü .. bir genç, Kondistable Emir Esededdin'in yanına gelerek..”; "Akşsm sirasında kuyunun kazllma işi bitince durumu Kondistabl'a arz ettiler. Onun üzerine Kondistabl, emirleri çağırarak ...; "O arada kale komutanı, kolu kanadı kırılmış olarak aciz vaziyette Emir Esededdin'in huzuruna çıktı" ${ }^{26}$. Emir-i Ahur veya Mîrâhur, Ortaçağ Türk İslam devletlerinde çok iyi bilinen ve yaygın biçimde kullanılan bir unvand1 ${ }^{27}$. Türkiye Selçukluları da bu kurum ve unvanı erken dönemlerinden itibaren kullandılar. Sultan I. İzzeddin Keykavus (1211-1220) ve I. Alaeddin Keykubad (1220-1237) dönemlerinin Selçuklu Emir-i Ahur'u Zeyneddin Beşâre idii ${ }^{28}$. Bir emire birden fazla unvan ve görev makamı verilmesi Selçuklularda sıkça karşılaşılan bir vakadır. Nitekim Zeyneddin Beşâre, Çaşnigir ve sübaşı1ık da yapmıştır. Zeyneddin gibi bir devlet görevlisi Emir-i Ahur unvanını taşırken, Eseddedin Ayaz'a Kondistabl unvanın verilmesi, öyle sanıyorum ki bir ayrıntıya işaret etmektedir. Emir-i Ahur, sarayın ahırları, atları, bakımları, teçhizatları v.s işlerinden sorumluyken, kondistabl makamı doğrudan askerlik hizmetiyle ilgili olmalıdır. Burada söz konusu olan görev süvarilerin yani atlı birliklerin komutanlığıdır.

Selçuklularda, kondistabl unvanıyla tanınan bir diğer şahsiyet Bizanslı Mihail Paleologos idi. İznik Laskaris devleti bünyesinde Büyük Konostavlos unvanıyla ordu komutanlığ görevindeyken, İmparator'a karşı komplo kurmakla suçlanması üzerine Mihail Paleologos, Selçuklu ülkesine iltica etti $(1256)^{29}$. Selçuklu hükümdarı II. İzzeddin Keykavus, Bizanslı mülteci Mihail Paleologos'u iyi karşıladı ve kendisine hizmet eden "Hıristiyanlardan oluşan birliklerin komutanlığına atadı" Selçuklu kaynaklarında Mihail'in adı doğrudan hiç geçmemektedir. Fakat gerek İbn Bibi gerekse de Aksarayî, Sultan İzzeddin Keykavus'un yakın devlet adamlarından birini Kondistabl (veya Kundistabl) bazen de Rum Kondistabl olarak zikretmektedirler ${ }^{31}$. Mihail'in kondistabl unvanıla askerî birlik komutanlığı görevine getirilirken, Selçuklu Emiri Fahreddin Arslan-Doğmuş'un Emir-i Ahur olması dikkat çekicidir. Selçuklu Sultanı İzzeddin Keykavus'la birlikte Aksaray yakınlarında, Mihail Paleologos'un da yer aldığı Moğol Baycu'ya karşı yapılan savaş Bizans kaynağı Akropolites’te şöyle anlatılmaktadır: "Bu sıralarda [Selçukluların] savaş bakımından durumu ciddi bir dönüm noktasındaydl; çünkü Takharios'lar [Moğollar] Müslümanların ülkesinin çoğu bölümünü talan ettikten sonra Axara [Aksaray] yakınlarında ordugah kurdular ve Persler [Selçuklular] için onlarla

\footnotetext{
${ }^{25}$ İbn Bibi, El-Evâmir, 259

26 İbn Bibi, El-Evâmir, 302-305.

${ }^{27}$ Abbas Sabbâğg, "Mîrâhur", Türkiye Diyanet Vakfi İslâm Ansiklopedisi, ( Erişim 10 Ekim 2021).

${ }^{28}$ N. Şaman Doğan, "Selçuklu Döneminde Siyasi ve Bani Kimliği İle Zeyneddîn Beşâre”, Turkish Studies 9/10, (2014), 957-976.

${ }^{29}$ Georgios Akropolites, Vekayiname, çev. B. Umar (İstanbul: Arkeoloji ve Sanat Yayınları, 2008), 129-131; D. J. Geanakoplos, "Emperor Michael Paleologus and the West 1258-1282", A Study in Byzantine-Latin Relations (Cambridge: 1959), 25.

${ }^{30}$ Akropolites, Vekayiname, s. 133; D. J. Geanakoplos, “Emperor Michael Paleologus and the West 1258-1282”, 29.

${ }^{31}$ İbn Bibi, El-Evâmir, 589; Kerîmüddin Mahmud-i Aksarayî, Müsâmeretü'l-Ahbar, çev. M. Öztürk (Ankara: TTK, 2000), 39, 40, 49.
} 
savaşmak artık bir gereksinme oldu. Böylece Selçuklular, Mihail Komnenos ${ }^{32}$ 'u Hıristiyanlardan oluşan ordu birliklerinin komutanı atadılar. ... Böylece Mihail Komnenos'un komutası altında bulunan ordu bölümü, karşılarında bulunan Moğollara karşı, onlarl hezimete uğratarak, yengi kazandı ve Mihail bu sırada en başta [çarpışmanın başında], mızrağtyla düşmanların komutanını gögssünden vurdu; bu kişi, bilenlerin söylediğine göre, bu vuruş nedeniyle klsa süre sonra öldü. Bunun üzerine Moğollar Mihail'in komutasındaki birlik tarafindan yenildiler ve geri çekilmeye başladılar. Ancak bu sırada Amyrkhouri [Emîr-i Ahur] makaminda bulunan bir Pers [Selçuklu Emiri Fahreddin Arslan-Doğmuş], önceden tasarladı̆̆ ihanet planını gerçekleştirdi ve kendi ordusunun bütününü yanına alarak Moğollara katıldı. Bunun üzerine savaş değişik gidiş aldl. O zaman dek düşmanları kovalamış olanlar şimdi gerilemeye başladılar ve sırtlarını düşman vuruşlarına döndüler. Böylece o sırada Selçuklulardan pek çoğu Moğolların oklarıyla öldürüldü̈,33. Mihail Paleologos, uğranılan mağlubiyet üzerine muhtemelen sultanla birlikte batıya çekildi. Sultan'ın Antalya civarına gittiği kesindir. Mihail belki de Kastamonu yöresinde saklandı ve Konya metropolitinin aracılığıyla İznik Bizans hükümdarından bağışlanma dileyerek $1258^{\prime}$ de geri ülkesine döndü ${ }^{34}$. Bilindiği üzere sonraki tarihi süreçte Mihail Paleologos önce imparator naipliğini elde etti ve 1261'de İstanbul'un Latinlerden geri alınmasıyla da kendisini imparator ilan ederek, Bizans'ın son hanedanı Paleologos'ların kurucusu oldu.

Aksarayî, II. İzzeddin Keykavus'un, İstanbul'a giderek, Rum imparatorundan 3 bin Frenk süvarisi desteği aldığını ve Konya'ya gelip tahta oturduğunu kaydediyor. Bundan sonra Aksarayi, son derece olumsuz ifadelerle eleştirdiği bir "Rum Kondistabl'dan" bahsediyor: "Saltanat ve ordu emirliğini elinde bulunduran Kondistabl'a Beylerbeyi Yavtaş'ın emirlik saltanatı son bulunca, beğlerbeğiliği makamı tamamen teslim edildi. Bu adam kâfirlik taassubundan dolayı Müslüman emirlere ve devlet büyüklerine karşı muhalefet ve kavga yolunu tutuyor, Sultan'ı oyun ve eğlenceye teşvik ediyor, dinî işlerden ve görevlerden alıkoyuyordu. O, hükmünü yürütmek ve istediğini yaptırmak için taht makamının, başkent Konya'dan Antalya'ya alınmasını teşvik ediyordu"35. Burada bahsedilen kondistabl, Mihail Paleologos olmasa gerektir. Muhtemelen Sultan'ın Hıristiyan dayılarından biriydi. Nitekim II. İzzeddin Keykavus, Anadolu'dan kaçıp, İstanbul'a iltica etmek zorunda kalınca, kondistabl, İmparator Mihail'e elçi olarak önceden gönderilmiş ve Sultan'ın İstanbul'a gelmesine aracılık etmişti. Selçuklu kaynaklarında bu olaydan sonra artık kondistabl unvanlı bir görevliden bahsedilmemektedir.

Sonuç itibarıyla XIII. yüzyıl boyunca Selçuklu devlet teşkilatında rastlanılan Batı kökenli unvan kondistabl, ücretli Frenk askerî birliklerinin Selçuklu ülkesinde görev yapmalarıyla tanınmış ve Selçuklularca benimsenmiştir. Selçuklu Türk kültür ve askeri teşkilatında kalıcı olmayan ve askeri idari yapıda önemli bir değişikliğe yol açmayan unvan, XIII. yüzyılın son çeyreğinde kaybolmuştur. Unvanın daha çok devşirme Hıristiyan kökenli emirler ve Mihail Paleologos gibi Hıristiyan inancında olanlara verildiği görülmektedir. Diğer taraftan belki de yönetimsel bir ihtiyaç dolayısıyla, Sarayda idari görevler için Emir-i Ahur unvanı tercih edilirken, askerî komutanlık için kondistabl tercih edilmiş olabilir.

\footnotetext{
${ }^{32}$ Mihail, Komnenos ailesiyle de akraba olduğu için bazen Komnenos bazen de Paleologos olarak adlandırılır.

${ }^{33}$ Akropolites, Vekayiname, 132-133.

${ }^{34}$ D. J. Geanakoplos," Emperor Michael”, 30.

${ }^{35}$ Aksarayi, Müsâmeretü'l-Ahbar, s. 39-40.
} 
Funding / Finansman: This research received no external funding. / Bu araştırma herhangi bir diş fon almamıştır.

Conflicts of Interest / Çıkar Çatışması: The author declare no conflict of interest. / Yazar, herhangi bir çıkar çatışması olmadığını beyan eder.

\section{KAYNAKÇA}

Akropolites, Georgios. Vekayiname. çev. B. Umar. İstanbul: Arkeoloji ve Sanat Yayınları, 2008.

Aksarayî, Kerîmüddin Mahmud. Müsâmeretü'l-Ahbar. çev. M. Öztürk. Ankara: TTK, 2000.

Altunsoy, Nazlı. Türkiye Selçukluları Döneminde Gayrimüslimler. Ankara: TTK, 2021.

Balivet, M. Romanie Byzantine et Pays de Rûm Turc. Histoire d'un Espace d'Imbrication Greco-Turque. İstanbul: 1994.

Cahen, Claude. Osmanlılardan Önce Anadolu. çev. E. Üyepazarcı. İstanbul: TVYY, 2000.

Demirkent, Işın. Haçlı Seferleri. İstanbul: Dünya Yayıncılık, 2004.

Demirkent, Ișın. Urfa Haçlı Kontluğu (1098-1118). I. Cilt. Ankara: TTK, 1990.

Ersan, M. Selçuklular Zamanında Anadolu'da Ermeniler. Ankara: TTK, 2007.

Favier, J. "Connetable". Encylopedia Universalis. Erișim 10 Ekim 2021.

Geanakoplos, D. J. "Emperor Michael Paleologus and the West 1258-1282". A Study in Byzantine-Latin Relations, Cambridge: 1959.

Göksu, E. Türkiye Selçuklularında Ordu. Ankara: TTK, 2010.

Hacıgökmen, Mehmet Ali. "Türkiye Selçuklu Devlet Adamlarından Eseddedin Ayaz". Selçuk Üniversitesi Türkiyat Araștırmaları Dergisi 25(2010).

İbn Bibi. El-Evâmirü'l-Alâ 'iyye fi'l-Umûri'l-Alâ'iyye Selçukname II. çev. M. Öztürk. Ankara: TTK, 2014.

Kazhdan, A. "Komes tou staulo" ve "Konostaulos". The Oxford Dictionary of Byzantium. Oxford: Oxford University Press, 2007. 1140, 1147.

Köymen, Mehmet Altay. Büyük Alâeddin Keykubad ve Zamanı. yay.haz. Salim Koca-Sinan Tarifci. İstanbul: Kronik, 2020.

Lamb, H. Haçlı Seferleri. çev. F. Dikmen. Ankara 2012.

Lewis, B. “Ifranj”, Encyclopédie de l'Islam. 4/16, 189-204. Leiden: BRILL, 2003.

Maalouf, A. Arapların Gözüyle Haçlı Seferleri. çev. M. Ali Kılıçbay. İstanbul: Telos Yayıncılık, 1997.

Rodolphe, G. "Le Grand Connétable", Recherches sur les institutions byzantines. 469-477. Berlin-Amsterdam, 1967.

Runciman, S. Haçlı Seferleri Tarihi. çev. F. Ișıltan. 3. Cilt. Ankara: TTK, 1986.

Sabbâğ, Abbas. "Mîrâhur". Türkiye Diyanet Vakfi İslâm Ansiklopedisi. Erişim 10 Ekim 2021.

de Saint Quentin, Simon. Bir Keşişin Anılarında Tatarlar ve Anadolu 1245-1248. çev. E. Özbayoğlu. Antalya: DAKTAV, 2006.

Şaman Doğan, Nermin. "Selçuklu Döneminde Siyasi ve Bani Kimliği İle Zeyneddîn Beşâre”. Turkish Studies. 9/10 (2014), 957-976.

Turan, Osman. Selçuklular Zamanında Türkiye Tarihi. İstanbul: Nakışlar Yayınevi, 1984. 